\title{
Peran Guru dalam Membangun Karakter dan Moral Siswa melalui Pendidikan Kewarganegaraan
}

Aulia Nur Hakim ${ }^{1}$, Dinie Anggraeni Dewi², Yayang Furi Furnamasari ${ }^{3}$

1,2,3Program Studi Pendidikan Guru Sekolah Dasar, Fakultas Ilmu Pendidikan,

Universitas Pendidikan Indonesia Kampus Cibiru

E-mail: aulianh@upi.edu, dinianggraenidewi@upi.edu,furi2810@upi.edu

\begin{tabular}{|c|c|}
\hline Article Info & Abstract \\
\hline $\begin{array}{l}\text { Article History } \\
\text { Received: } 2021-11-02 \\
\text { Revised: 2021-11-22 } \\
\text { Published: } 2021-12-04\end{array}$ & $\begin{array}{l}\text { The moral decline of the current generation of the Indonesian nation threatens to lose } \\
\text { the identity of the Indonesian nation, which adheres firmly to the values of Pancasila. } \\
\text { Through Citizenship Education, students will be trained to think critically, be } \\
\text { responsible, have a nationalist spirit and behave democratically which can build the } \\
\text { character and morals of students at school. This study aims to examine how Citizenship }\end{array}$ \\
\hline $\begin{array}{l}\text { Keywords: } \\
\text { Character; } \\
\text { Moral; } \\
\text { Teacher's Role; } \\
\text { Education; } \\
\text { Citizenship. }\end{array}$ & $\begin{array}{l}\text { Education can shape the character and morals of students and how the role of teachers } \\
\text { in building the character and morals of students in schools. The method used in this } \\
\text { study is a qualitative descriptive method. That is by presenting data based on facts in } \\
\text { the field. The result of the research conducted is that Citizenship Education can help } \\
\text { develop students' character and morals through the cultivation of positive values } \\
\text { based on the values of Pancasila. Teachers also have an obligation to educate students, } \\
\text { train themselves and motivate their students to become moral and dignified human } \\
\text { beings. That way, the moral and character Indonesian generation will remain attached } \\
\text { to the soul of the Indonesian nation. }\end{array}$ \\
\hline
\end{tabular}

\begin{tabular}{l}
\hline Artikel Info \\
\hline Sejarah Artikel \\
Diterima: 2021-11-02 \\
Direvisi: 2021-11-22 \\
Dipublikasi: 2021-12-04
\end{tabular}

Kata kunci:

Karakter;

Moral;

Peran Guru;

Pendidikan;

Kewarganegaraan.

\begin{abstract}
Abstrak
Lunturnya moral generasi bangsa Indonesia saat ini mengancam hilangnya jati diri bangsa Indonesia yang berpengang teguh pada nilai-nilai Pancasila. Melalui Pendidikan Kewarganegaraan siswa akan dilatih untuk berpikir kritis, bertanggung jawab, berjiwa nasionalis serta berperilaku demokratis yang dapat membangun karakter serta moral siswa di sekolah. Penelitian ini bertujuan untuk mengkaji bagaimana Pendidikan Kewarganegaraan dapat membentuk karakter dan moral siswa serta bagaimana peran guru dalam membangun karakter dan moral siswa di sekolah. Metode yang digunakan dalam penelitian ini adalah metode deskriptif kualitatif, yaitu dengan menyajikan data berdasarkan fakta yang ada di lapangan. Hasil dari penelitian yang dilakukan adalah Pendidikan Kewarganegaraan dapat membantu mengembangkan karakter dan moral siswa melalui penanaman nilai-nilai postitif yang didasarkan pada nilai-nilai Pancasila. Guru juga memiliki kewajiban untuk mendidik siswa, melatih diri siswa serta memotivasi anak didiknya agar dapat menjadi manusia yang bermoral dan bermartabat. Dengan begitu, generasi bangsa indonesia yang bermoral dan berkarakter akan tetap melekat pada jiwa bangsa Indonesia.
\end{abstract}

\section{PENDAHULUAN}

Penanaman nilai moral sangat penting dilakukan kepada setiap warga negara sebab nilai moral menjadi suatu hal yang dapat diinvestasikan negara kepada generasi saat ini untuk masa yang akan dating, dengan menanamkan nilai moral, hal ini bertujuan untuk mengubah perilaku, sikap, watak, dan kepribadian seseorang yang berlandaskan nilai-nilai kebenaran, norma, atau prinsip yang ada sesuai dengan ideologi Pancasila. Pendidikan menjadi salah satu cara untuk menanamkan nilai tersebut kepada setiap orang terutama siswa di sekolah. Di sekolah anak akan diberikan edukasi, pemahaman serta pelaksanaan praktik yang akan dibimbing oleh gurunya di sekolah. Mata pelajaran PKn menjadi sebuah upaya untuk menanamkan jiwa pancasilais, membentuk karakter anak, serta menanamkan nilai-nilai moral sejak anak kecil, agar setelah menginjak usia dewasa karakter yang baik telah menjadi sebuah kebiasaan bagi dirinya. PKn merupakan bagian dari pendidikan nasional dalam rangka mencerdaskan generasi bangsa serta menciptakan generasi yang memiliki moral dan jiwa nasionalis (Dewi \& Ulfah, 2021:503). Pendidikan Kewarganegaraan memiliki tujuan yaitu untuk membangun peserta didik yang berkarakter dan beradab yang sejalan dengan nilai dari Pancasila yang menjadi dasar negara Indonesia. Dalam Undang-undang No. 20 Tahun 2003 mengenai sistem pendidikan nasional, mata pelajaran PKn 
menjadi salah satu upaya dalam membantu siswa mendapatkan ilmu pengetahuan serta kemahiran dasar yang berkaitan dengan hubungan warga negara dan pendidikan terdahulu dengan tujuan setiap warga bisa menjadi tumpuan negara, serta dalam UU RI No. 20 Tahun 2003 tentang Sisdiknas Pasal 37 Ayat (1) huruf b yang menyatakan bahwa kurikulum pendidikan dasar dan menengah wajib memuat pendidikan kewarganegaraan, hal ini berarti negara mewajibkan mata pelajaran Pendidikan Kewarganegaraan dilaksanakan di setiap sekolah.

Seperti yang kita ketahui saat ini, karakter bangsa indonesia dari waktu ke waktu sudah mulai luntur seiring dengan perkembangan zaman. Isa, dkk.(2021, hlm 68) mengatakan jika generasi abad 21, saat ini dihadapkan pada berbagai tantangan global yang sangat kompleks. Situasi seperti ini mengakibatkan sumber daya manusia yang berkarakter sangat dibutuhkan. Karakter yang dibangun merupakan alat utuk menghadapi segala tantangan bangsa termasuk persaingan antar negara (Jannah, 2014:164). Hal itu tentunya harus menjadi perhatian khusus terutama bagi guru. Lunturnya karakter tersebut terlihat seperti pada beberapa permasalahan yang sering kita jumpai seperti saling egois atau mementingkan dirinya sendiri dan tidak memikirkan orang lain, korupsi, kurangnya solidaritas, kurangnya kerja sama, kurangnya cinta tanah air, dan tidak jujur. Bahkan seperti yang dikatakan Hakim \& Dewi (2021, hlm 240) saat ini Pancasila hanya dijadikan sebagai sebuah simbol untuk kegiatan upacara semata. Jika hal tersebut dibiarkan, maka generasi saat ini perlahan akan kehilangan jati dirinya dan ideologi Pancasila akan memudar seiring dengan perubahan zaman.

Berdasarkan yang sudah dipaparkan diatas, peneliti tertarik untuk membahas beberapa permasalahan, yaitu 1) Bagaimana pendidikan kewarganegaraan dapat membangun karakter dan moral siswa di sekolah? 2) Bagaimana peran guru dalam membangun karakter siswa? Penelitian ini bertujuan untuk mengkaji beberapa hal yaitu: 1) Membangun karakter dan moral siswa melalui pendidikan kewarganegaraan; dan 2) Peran guru dalam membangun karakter siswa.

\section{METODE PENELITIAN}

Peneliti menggunakan pendekatan kualitatif dengan metode deskriptif yaitu dengan cara mengumpulkan, menganalisis, membuat gambaran dan mempersingkat segala kondisi dan situasi dari data yang telah terkumpul. Denzin \&
Lincoln (1944) dalam Anggito \& Setiawan (2018, hlm 7) menyebut jika penelitian kualitatif merupakan penelitian dengan penggunaan latar naturalis yang bermaksud untuk menggambarkan peristiwa yang ada. Penelitian deskriptif kualitatif menyajikan out put data sesuai dengan kenyataan yang didapat tanpa adanya unsur kebohongan atau manipulatif, semuanya didasarkan pada kenyataan di lapangan. Tujuan dari penelitian kualitatif yaitu untuk memberikan gambaran, menjelaskan dan merespon secara rinci topik yang dibahas dan diteliti dengan cara mempelajari semaksimal mungkin suatu kejadian, dalam hal ini, peneliti berperan penting karena menjadi kunci keberhasilan dalam menentukan hasil penelitian yang telah dibuat.

\section{HASIL DAN PEMBAHASAN}

A. Membangun Karakter dan Moral Siswa Melalui Pendidikan Kewarganegaraan

Moral bangsa indonesia di zaman saat ini sangat memprihatinkan, terlebih pada anak usia sekolah dimana sikap dan moral yang tercermin jauh dari nilai sila-sila Pancasila. Dalam hal ini, tentu saja sekolah memiliki tanggung jawab atas hal tersebut dalam memberikan pemahaman dan penanaman nilai-nilai moral sebab karakter siswa tidak dapat terbentuk dengan sendirinya tanpa adanya pengarahan dari luar. Penekanan nilai-nilai seperti saling menghormati, menghargai, demokratis, tolong menolong, jujur, hormat, kreatif, bertanggung jawab, adil, peduli terhadap sesama, cinta tanah air dan lain-lain menjadi tujuan utama dari pembangunan karakter siswa (Sudrajat, 2011:5556). Hal yang sama juga dikemukakan oleh (Triatmanto, 2010:192) bahwa pengembangan nilai-nilai yang sudah disebutkan di atas harus bisa siswa implementasikan dalam kehidupan, baik di sekolah maupun di masyarakat. Sehingga jika siswa berpegang teguh pada nilai-nilai tersebut, maka ia akan dipandang sebagai manusia seutuhnya.

Sejalan dengan (Andrian, 2017:18), Pendidikan Kewarganegaraan memiliki hubungan yang erat dalam mengembangkan karakter seperti yang dinyatakan oleh Cogan (1998:13) bahwa mata pelajaran Pendidikan Kewarganegaraan berperan dalam mengembangkan karakteristik seorang warga negara. Jadi, dalam hal ini seorang warga negara memerlukan pedidikan yang formal agar karakternya dapat dibentuk secara terarah sesuai dengan apa yang diharapkan. Berdasa- 
rkan penelitian yang telah dilakukan oleh Sunarti (2019:9-10), ia menjelaskan jika Pendidikan Kewarganegaraan dan pembangunan karakter siswa saling berhubungan. Sebab terdapat banyak nilai yang dapat membangun karakter di dalamnya, diantaranya yaitu mencerna, menunjukan dan melakukan berbagai aturan serta nilai-nilai luhur yang terdapat pada kehidupan seharihari. Melalui Pendidikan Kewarganegaraan siswa juga diajarkan untuk peduli terhadap lingkungan dan sosial, dengan begitu siswa akan disayangi dan dijaga oleh masyarakat sekitar.

Selaras dengan penjelasan di atas, Simorangkir dalam Zurohman \& Baharudin (2021:26), menyatakan jika PKn memberi konsep yang relevan dengan menanamkan kepada peserta didik cara berpikir, bertindak, dan mempraktikkan nilai moral yang sesuai dengan Pancasila. Serta Pkn menjadi sebuah mata pelajaran untuk mempertahankan dan melestarikan nilai moral dan norma yang berlaku di Indonesia. Sehingga ditarik kesimpulan bahwa Pendidikan Kewarganegaraan memiliki peran yang sangat penting dalam membangun karakter sebab terdapat nilai-nilai kebajikan yang dapat siswa pelajari, pahami dan diterapkan pada kehidupan sehari-hari, Pkn juga menjadi sebuah upaya pelestarian nilai moral yang ada di Indonesia.

\section{B. Peran Guru Dalam Membangun Karakter} Siswa

Menurut (Sakti, 2018) upaya pembangunan karakter anak tidak terpaku pada lingkungan lembaga formal saja (sekolah), namun lebih dari itu. Pendidikan karakter dapat diberikan kepada anak dimana saja dan kapan saja, hal itu dapat dilakukan di lingkungan keluarga, lembaga pendidikan, masyarakat, termasuk di lingkup luar negara. Karena pendidikan karakter tidak dibatasi oleh tempat dan waktu. Maka pendidikan dan pembentukan karakter menjadi tanggung jawab setiap individu termasuk guru di sekolah yang menjadi pendamping anak ketika di sekolah. Guru tidak hanya berperan sebagai pengajar di sekolah, namun juga berkewajiban untuk membangun peserta didik yang berkarakter, guru memiliki tanggung jawab yang berat terhadap perkembangan karakter peserta didik, terlebih ditengah kemajuan teknologi yang terus berkembang pesat.
Dengan adanya teknologi, setiap manusia diberi kemudahan dalam berkomunikasi, mencari informasi, bahkan dengan adanya teknologi ini manusia dapat menghasilkan uang melalui aplikasi. Segala kemudahan yang tersaji memang banyak membantu manusia dalam menjalani kehidupannya, namun selain daripada itu tentu saja terdapat dampak negatif yang dihasilkan. Misalnya, sebagian besar orang pasti mengenal aplikasi hiburan seperti Tiktok. Aplikasi tersebut banyak digandrungi oleh semua orang terlebih lagi kaum muda. Aplikasi tersebut memiliki sisi positif dan negatifnya, jika digunakan dengan bijak aplikasi tersebut dapat membantu siswa misalnya dalam menguasai trik menghitung matematika, dan sebagainya. Tetapi ada pula sisi negatifnya, seperti banyak video anak usia sekolah hingga dewasa yang berjoget-joget dengan berlebihan, menampilkan video yang tidak pantas dicontoh oleh anak-anak dan remaja di zaman sekarang, hal tersebut tentu saja merusak moral anak generasi saat ini.

Guru berkewajiban untuk mendidik peserta didik, melatih diri peserta didik, memotivasi anak didik, dan mengarahkan peserta didiknya agar dapat menjadi manusia yang bermoral dan bermartabat (Wardani, 2010: 237). Guru perlu memberikan pengarahan kepada siswa untuk memilih mana yang baik dan mana yang buruk bagi dirinya. Selain itu, guru juga perlu menjadi panutan yang baik, sebab setiap perilaku yang ditunjukan oleh guru di sekolah akan dijadikan contoh oleh peserta didik. Maka, sudah terlihat jelas jika guru di sekolah memiliki peranan yang penting dan kompleks.

Berdasarkan penelitian yang telah dilakukan oleh Rezita Anggraini, ia memiliki strategi pembelajaran untuk membantu peserta didik dalam mengembangkan karakternya, yaitu dengan memasukan sikap gotong royong, membiasakan budaya yang ada di lingkungan, serta penerapan praktik aktivitas sehari-hari yang dilakukan di rumah dan di lingkungan sosial berbentuk lembar melakukan shalat, cek aktivitas belajar serta buku penghubung. Hal ini dapat mempengaruhi karakter siswa sebab terdapat keterlibatan antara guru, orang tua serta dorongan motivasi dari dalam diri anak sendiri, ketika anak sudah mulai menunjukan kebiasaan tersebut, maka strategi yang digunakan dapat terus diterapkan. Adapun faktor yang menghambat anak dalam 
melakukan hal tersebut, diantaranya adalah rasa malas, serta kesulitan beradaptasi dengan strategi pembelajaran yang dilakukan saat awal pembiasaan (Astuti, 2019:56-57). Agar strategi yang digunakan dapat terlaksana dengan baik, maka diperlukan strategi yang terstruktur, terpadu serta terarah.

Ada beberapa metode atau cara dalam menanamkan moral pada diri peserta didik diantaranya metode komunikasi, bermain, memberikan tugas, serta bercerita. Metode tersebut bisa diselaraskan dengan karakteristik serta kondisi fisik anak. Menanamkan nilai moral melalui pendidikan tidak formal dapat dilaksanakan di lingkungan keluarga, sedangkan pada pendidikan formal dapat dilakukan di sekolah melalui kegiatan pembelajaran yang melibatkan guru, lembaga pendidikan serta diri anak sendiri (Yuliana, 2015), adapun Indikator Keberhasilan Pembentukan Karakter siswa dapat dilihat melalui beberapa hal (Sukemi, 2012:358):

1) Kondisi kelas yang rapih, bersih dan nyaman ditempati.

2) Kedisiplinan siswa serta warga sekolah yang tercermin melalui ketepatan waktu saat datang ke sekolah dan mentaati aturan yang berlaku.

3) Siswa menunjukan sikap dan perilaku yang sopan, rapih serta ramah terhadap orang lain.

4) Kondisi di sekolah yang selalu terlihat religius, melalui kegiatan berdoa sebelum dan sesudah belajar, shalat dhuha bersama, serta jiwa nasionalis siswa tercermin dengan selalu mengikuti kegiatan upacara bendera, menyanyikan lagu wajib dan lagu daerah saat awal pembelajaran serta mengamalkan nilai sila-sila pancasila pada kehidupan sehari-hari.

5) Siswa menunjukan sikap jujur dengan tidak menyontek saat ujian.

\section{SIMPULAN DAN SARAN}

\section{A. Simpulan}

Diera kemajuan teknologi saat ini pembangunan karakter serta moral menjadi suatu hal yang sangat vital, pendidikan Kewarganegaraan memiliki keterkaitan dengan pengembangan karakter sebab melalui mata pelajaran tersebut karakteristik peserta didik dikembangkan sesuai dengan tujuan dari mata pelajaran PKn itu sendiri. Sekolah serta guru ikut bertanggung jawab dalam perkembangan karakter siswa sehingga diperlukan pendampingan kepada siswa agar karakter yang dikembangkan dapat tercapai sesuai harapan. Guru perlu menjadi contoh yang baik bagi siswa, sebab apapun yang dilakukan oleh guru akan dijadikan panutan oleh siswa. Adapun indikator keberhasilan dalam pembentukan karakter siswa, diantaranya kondisi kelas yang terstruktur, kedisiplinan selalu tercermin pada diri siswa, siswa menunjukan perilaku yang sopan dan rapih, kondisi kelas terlihat religius serta sikap jujur tercermin pada diri siswa.

\section{B. Saran}

Adapun saran yang dapat disampaikan peneliti untuk peneliti selanjutnya diharapkan dapat menambah fokus dan kajian yang belum diteliti pada penelitian ini.

\section{DAFTAR RUJUKAN}

Andrian, A. (2017). Pengembangan Karakter Siswa Melalui Pendidikan Kewarganegaraan. Untirta Civic Education Journal, 2(1), 17-30. https://doi.org/10.30870/ucej.v2i1.2799

Anggito, A., Setiawan, J.(2018). Metodologi Penelitian Kualitatif. Sukabumi: CV Jejak.

ASTUTI, F. (2019). Strategi Guru Kelas Dalam Membentuk Karakter Peserta Didik Di Sdit Permata Bunda Iii Bandar Lampung. Journal of Chemical Information and Modeling, 53(9), 1689-1699.

Departemen Pendidikan Nasional. (2003). Undang-undang Republik Indonesia No. 20 Tahun 2003 tentang Sistem Pendidikan Nasional.

Dewi, D. A., \& Ulfiah, Z. (2021). PERANAN PENDIDIKAN KEWARGANEGARAAN TERHADAP PEMBANGUNAN KARAKTER BANGSA.Jurnal Pendidikan Kewarganegaraan Undiksha, 9(2), 499-506.

Fairuz, S., Isa, P., \& Dewi, D. A. (2021). DALAM MENGEMBANGKAN KARAKTER SISWA DI ERA GLOBALISASI. 6(1), 66-71.

Hakim, A. N., \& Dewi, D. A. (2021). Penyimpangan dalam Masyarakat Luas. Jurnal Kewarganegaraan, 5(1), 239-248.

Isa, S. F. P., \& Dewi, D. A. (2021). PERAN DAN TANTANGAN PENDIDIKAN KEWARGANEGARAAN DALAM MENGEMBANGKAN 
KARAKTER SISWA DI ERA GLOBALISASI. Harmony: Jurnal Pembelajaran IPS dan PKN, 6(1), 66-71.

Jannah, F. (2014). Urgensi Pendidikan Karakter Di Sekolah. Journal.Stitaf.Ac.Id, 05(01), 167-184.

https://journal.stitaf.ac.id/index.php/cend ekia/article/view/19

Sakti, B. P. (2018). Indikator Pengembangan Karakter Siswa Sekolah Dasar. Magistra, 29(101), 1-10. https://doi.org/10.31227/osf.io/pucw9

Sudrajat, A. (2011). Mengapa Pendidikan Karakter. Jurnal Pendidikan Karakter, I(1), 47-58.

https://doi.org/10.21831/jpk.v1i1.1316

Triatmanto, T. (2010). Tantangan implementasi pendidikan karakter di sekolah. Cakrawala Pendidikan, (3), 82363.
Wardani, K. (2010). Peran Guru Dalam Pendidikan Karakter Menurut Konsep Pendidikan Ki Hadjar Dewantara. November, 8-10.

Yuliana, L. (2015). Penanaman Nilai-Nilai Moral Pada Anak Usia Dini. Jurnal Ilmiah WUNY, 15(1),

$1-10$. https://doi.org/10.21831/jwuny.v15i1.35 27

Zurohman, A., \& Bahrudin, B. (2021). Peran PKn dalam Membentuk Warga Negara Berpancasila. Journal Civics \& Social Studies, 5(1), 24-30. https://doi.org/10.31980/civicos.v5i1.793 